DOI: http://dx.doi.org/10.18203/2320-1770.ijrcog20162089

Research Article

\title{
Rupture uterus: a clinical analysis
}

\section{Soma Bandyopadhyay*, Sipra Singh}

Department of Obstetrics and Gynaecology, Katihar Medical College, Bihar, India

Received: 26 April 2016

Accepted: 02 June 2016

*Correspondence:

Dr. Soma Bandyopadhyay,

E-mail: somapb@gmail.com

Copyright: (C) the author(s), publisher and licensee Medip Academy. This is an open-access article distributed under the terms of the Creative Commons Attribution Non-Commercial License, which permits unrestricted non-commercial use, distribution, and reproduction in any medium, provided the original work is properly cited.

\section{ABSTRACT}

Background: Rupture uterus is one of the major causes of maternal mortality. It not only causes mortality, the survivor suffers much morbidity also. Finding out the etiology of rupture uterus, can help us to reduce its incidence. Present study is undertaken to know the scenario of rupture uterus in our institution.

Methods: It is a retrospective study from 2011 to 2015. Data was obtained from the record section of the hospital. All rupture uterus cases were included. Previous mode of delivery, etiologies of rupture, operation performed etc. were studied.

Results: Incidence of rupture uterus was 1 in 618 deliveries. Maternal mortality was $25 \%$, perinatal mortality was $88.5 \%$. Unbooked cases were $90.4 \%$. Previous mode of delivery was vaginal delivery in $67.3 \%$ cases. Most common cause of rupture uterus was oxytocin overdose $(26.9 \%)$ and handled labor $(30.8 \%)$. Complete rupture was found in $75 \%$ cases. Subtotal hysterectomy was performed in $46.1 \%$ cases.

Conclusions: Mandatory antenatal care (90.4\% unbooked cases) and safe institutional delivery (oxytocin overdose and handled labor common cause) may change the rupture uterus scenario.

Keywords: Oxytocin, Handled labor, Subtotal hysterectomy, Unbooked case, Maternal mortality

\section{INTRODUCTION}

Rupture uterus is a potentially catastrophic condition during pregnancy or delivery, when myometrial wall integrity is breached. It is of 2 types - incomplete and complete. In incomplete variety the peritoneum is not ruptured, it is intact. In complete variety the peritoneum also ruptured and the uterine content (e.g. fetus, placenta, amniotic fluid etc.) may spill into the peritoneal cavity or within the leaves of the broad ligament. Uterine scar dehiscence is the asymptomatic separation or thinning of the uterine previous scar without involving the peritoneal coat and without any hemorrhage. ${ }^{1}$

A uterine rupture is a life-threatening condition for both the mother and fetus. Prevalence ranges from 1 in 2000 to 1 in 200 deliveries ${ }^{1}$ Rupture due to obstructed labour has been reduced, but total uterine rupture scenario has not been changed due to increased incidence of caesarean section (scar rupture). Present study aims to analyse the clinical scenario of rupture uterus in our set-up.

\section{METHODS}

This is a retrospective study of last 5 years (2011-2015) at Katihar Medical College, Bihar, India. The data was obtained from the register available in the medical record section of the hospital. Institutional ethics committee approval has been obtained. Cases with rupture uterus were included in the study. The age, parity, (booked/unbooked), past history of caesarean section, type (complete/incomplete), treatment (repaired/hysterectomy), blood transfusion, condition of the fetus (alive/dead), post-operative complication, maternal mortality were analyzed. Total number of deliveries within this period was recorded and incidence rate was calculated. 


\section{RESULTS}

In 5 years total number of deliveries was 32,143 and number of rupture uterus was 52 . So the incidence of rupture uterus is 1 in 618 deliveries. Out of the 52 patients 13 expired (25\%). Regarding baby, out of 52 cases 46 expired (88.5\%). Year wise incidence is shown below (Table 1).

Ages between 26-30 years comprised highest (40.4\%). Gravida 2, 3, 4 contributed almost equal (23-25\%). Most of the patients had received either no or inadequate antenatal check-up (unbooked cases) (Table 2).

Table 1: Incidence.

\begin{tabular}{|llllll|} 
Year & No. of case & No. of Delivery & Incidence rate & Maternal Mortality (\%) & Perinatal mortality (\%) \\
\hline 2011 & 13 & 3695 & 1 in 284 deliveries & $5(38.5 \%)$ & $12(92.3 \%)$ \\
\hline 2012 & 17 & 7511 & 1 in 442 deliveries & $3(17.6 \%)$ & $15(88.2 \%)$ \\
\hline 2013 & 10 & 7348 & 1 in 735 deliveries & $1(10 \%)$ & $9(90 \%)$ \\
\hline 2014 & 7 & 6727 & 1 in 961 deliveries & $3(42.8 \%)$ & $6(85.7 \%)$ \\
\hline 2015 & 5 & 6862 & 1 in 1372 deliveries & $1(20 \%)$ & $4(80 \%)$ \\
\hline Total & $\mathbf{5 2}$ & $\mathbf{3 2 1 4 3}$ & $\mathbf{1}$ in $\mathbf{6 1 8}$ deliveries & $\mathbf{1 3}(\mathbf{2 5 \%})$ & $\mathbf{4 6}(\mathbf{8 8 . 5} \%)$ \\
\hline
\end{tabular}

Table 2: Age, parity, booked/unbooked distribution of rupture uterus.

\begin{tabular}{|lllllllll|}
\hline Age (year) & No. & $\%$ & Gravida & No. & $\%$ & Booked/unbooked & No. & $\%$ \\
\hline $20-25$ & 14 & 26.9 & 2 & 12 & 23 & Booked & 5 & 9.6 \\
\hline $26-30$ & 21 & 40.4 & 3 & 13 & 25 & Unbooked & 47 & 90.4 \\
\hline $31-35$ & 10 & 19.2 & 4 & 13 & 25 & Total & $\mathbf{5 2}$ & \\
\hline $36-40$ & 6 & 11.5 & 5 & 10 & 19.2 & & \\
\hline $41-45$ & 0 & 0 & 6 & 1 & 1.9 & & \\
\hline $46-50$ & 1 & 1.9 & 7 & 1 & 1.9 & & \\
\hline Total & $\mathbf{5 2}$ & & 8 & 0 & 0 & & \\
\hline & & & 9 & 1 & 1.9 & & \\
\hline & & & 10 & 0 & 0 & & \\
\hline & & & 11 & 1 & 1.9 & & \\
\hline & & & Total & $\mathbf{5 2}$ & & & \\
\hline
\end{tabular}

Table 3: Gestational age and previous mode of delivery.

\begin{tabular}{|llllll|}
\hline Gestational age (weeks) & No. & $\%$ & Previous delivery & No. & $\%$ \\
\hline 40 & 29 & 55.8 & Vaginal delivery & 35 & 67.3 \\
\hline 39 & 2 & 3.8 & Previous 1 LSCS & 14 & 26.9 \\
\hline 38 & 1 & 1.9 & Previous 2 LSCS & 2 & 3.8 \\
\hline 37 & 4 & 7.7 & Classical CS & 1 & 1.9 \\
\hline 36 & 3 & 5.8 & Total & $\mathbf{5 2}$ & \\
\hline 32 & 3 & 5.8 & 32 & \\
\hline 28 & 1 & 1.9 & 28 & \\
\hline 24 & 1 & 1.9 & 24 & \\
\hline$?$ & 8 & 15.4 & $?$ & & \\
\hline Total & $\mathbf{5 2}$ & & & & \\
\hline
\end{tabular}

LSCS-lower segment caesarean section, CS-caesarean section

Regarding gestational age term pregnancy was highest (40 weeks-55.8\%). Past obstetric event revealed that vaginal delivery was the commonest mode of delivery (67.3\%) (Table 3).
Oxytocin overdose and handled labour were the most common cause of rupture uterus. Subtotal hysterectomy was performed in $46.1 \%$ cases (Table 4). Complete transverse rupture was the commonest type of rupture found $(44.2 \%)$ (Table 5). 
Table 4: Causes of rupture uterus and types of operation performed.

\begin{tabular}{|c|c|c|c|c|c|}
\hline Causes & No. & $\%$ & Type of operation & No. & $\%$ \\
\hline Oxytocin overdose & 14 & 26.9 & Subtotal hysterectomy & 24 & 46.1 \\
\hline Handled labour & 16 & 30.8 & $\begin{array}{l}\text { Subtotal hysterectomy with bladder injury } \\
\text { repair }\end{array}$ & 5 & 9.6 \\
\hline Obstructed labour & 5 & 9.6 & $\begin{array}{l}\text { Subtotal hysterectomy with colporrhexis } \\
\text { repair }\end{array}$ & 1 & 1.9 \\
\hline Caesarean scar rupture & 11 & 21.6 & Total abdominal hysterectomy & 1 & 1.9 \\
\hline Malpresentation & 4 & 7.7 & Hysterectomy total & 31 & 59.6 \\
\hline Multipara & 2 & 3.8 & & & \\
\hline \multirow[t]{7}{*}{ Total } & 52 & & Repair of uterine rent & 4 & 7.7 \\
\hline & & & Repair with bilateral tubectomy & 6 & 11.5 \\
\hline & & & Repair with bladder injury repair & 1 & 1.9 \\
\hline & & & Peritoneal wash (repaired outside) & 1 & 1.9 \\
\hline & & & Repaired total & 12 & 23 \\
\hline & & & Operation could not be done before death & 9 & 17.3 \\
\hline & & & Total & 52 & \\
\hline
\end{tabular}

Table 5: Type of rupture.

\begin{tabular}{|lll|}
\hline Type of rupture & No. & \\
\hline Complete rupture & & 44.2 \\
\hline Transverse & 23 & 9.6 \\
\hline Transverse with bladder injury & 5 & 3.8 \\
\hline Transverse with posterior wall tear & 2 & 1.9 \\
\hline Transverse with broad ligament hematoma & 1 & 3.8 \\
\hline Vertical & 2 & 3.8 \\
\hline Vertical with colporrhexis & 2 & 1.9 \\
\hline Vertical with bladder injury & 1 & 3.8 \\
\hline 'J' shaped tear & 2 & 1.9 \\
\hline Inverted 'T' shaped tear & 1 & 7.7 \\
\hline Incomplete rupture & 4 & 17.3 \\
\hline Clinical diagnosis & 9 & \\
\hline Total & $\mathbf{5 2}$ & \\
\hline
\end{tabular}

Table 6: Postoperative complication, blood transfusion and hospital stay.

\begin{tabular}{|llllllll|}
\hline Postoperative complication & Number & Blood transfusion & Number & \multicolumn{3}{c|}{ Hospital stay (day) } \\
\hline Wound gapping & 5 & 1 unit & 9 & Day & Number & Day & Number \\
\hline Fever & 9 & 2 units & 12 & Few hours & 10 & 9 & 5 \\
\hline Burst abdomen & 1 & 3 units & 8 & 1 & 1 & 10 & 4 \\
\hline Paralytic ileus & 3 & 4 units & 10 & 2 & 1 & $11-15$ & 13 \\
\hline Respiratory distress & 2 & 5 units & 1 & 3 & 1 & $16-20$ & 1 \\
\hline Jaundice & 1 & Total & $\mathbf{4 0}$ & 7 & 1 & $21-25$ & 4 \\
\hline Acute Renal failure & 1 & & & 8 & 8 & $26-30$ & 3 \\
\hline
\end{tabular}

Fever in the post-operative period was the most common complication, followed by wound gapping. Blood transfusion was needed for 40 patients. Most of the expired cases stayed in the hospital for few hours only. Other cases mostly were discharged between 8-15 days. (Table 6) Twelve patients $(23 \%)$ were presented with shock. 


\section{DISCUSSION}

Due to various reasons e.g. lack of health education, ignorance, poverty etc. good number of pregnant mother does not come for regular antenatal check-up, and undergoes home delivery, instead of safe institutional delivery. They rush to the obstetrics casualty in moribund condition due to prolonged labour, obstructed labour, shock, rupture uterus etc. Due to its grave consequences the obstetrician should be very vigilant to consider rupture uterus in presence of pain abdomen, vaginal bleeding, loss of station of presenting part, and nonreassuring fetal heart rate pattern in CTG (cardiotocography).

The incidence of rupture uterus was 1 in 618 deliveries. Other studies found the incidence as 1 in 1633 deliveries $(0.061 \%), 1$ in 346 deliveries. ${ }^{2,3}$ Age of the patient varies from 20-50 years (26-30 years comprised 40.4\%) and gravida 2-4 contributes highest. These findings are comparable with other studies. ${ }^{2,3}$ Unbooked case was found in $90.4 \%$ cases. In other studies unbooked cases was $76.6 \%, 80 \%$. $^{2,4}$

Previous uterine scar was responsible for rupture uterus in $70.2 \%, 50.6 \%, 63.3 \%$ cases. $^{2-4}$ In present study uterine scar rupture was found in $21.6 \%$ cases. Among past operative history, prior caesarean section was commonest. $^{2-5}$ Obstructed labour was the etiology in $28.6 \%, 26.6 \%$ cases; whereas in present study it was $9.6 \%$ cases. $^{2,4}$ This decreasing incidence of obstructed labour is a good sign.

Complete rupture was found in 39 cases $(75 \%)$, another study found $66 \%$ cases. $^{3}$ Repair of the rent was done in $83 \%, 58.3 \%, 54 \%$ cases; in present study in $23 \%$ cases repair was done. ${ }^{2-4}$ Maternal mortality was $25 \%$. In other studies maternal mortality was $2.76 \%, 3.33 \%$. ${ }^{3,4}$ It is more here because our hospital received many referral cases from the surrounding area in last hours. Perinatal mortality was $94.07 \%, 78.66 \%$; in present study $88.5 \%$.,4

\section{CONCLUSION}

Global scenario of decreasing trend of maternal mortality due to rupture uterus hinting towards the notion that rupture uterus is a preventable condition. Oxytocin overdose, previous caesarean section, grand multiparty, neglected labour, malpresentation etc. are precipitating factors for rupture uterus. Health education to come for regular antenatal check-up is the cornerstone to prevent this fatality $(90.4 \%$ unbooked cases). Also safe institutional delivery is to be promoted (oxytocin overdose and handled labour is the common cause). Early referral also can save many mothers' life.

Funding: No funding sources

Conflict of interest: None declared

Ethical approval: The study was approved by the Institutional Ethics Committee

\section{REFERENCES}

1. Dutta DC. Pregnancy with prior caesarean delivery. In: Konar H ed DC Dutta's Textbook of Obstetrics. $8^{\text {th }}$ ed. New Delhi, Jaypee Brothers Medical Publishers (P) Ltd.; 2015:381-386.

2. Sinha M, Gupta R, Gupta P, Rani R, Kaur R, Singh $\mathrm{R}$. Uterine rupture: a seven year review at a tertiary care hospital in New Delhi, India. Ind J Com Med. 2016;41:45-9.

3. Sahu L. A 10 year analysis of uterine rupture at a teaching institution. $\mathrm{J}$ Obstet Gynecol India. 2006;56:502-6.

4. Rashmi, Radhakrisknan G, Vaid NB, Agarwal N. Rupture uterus-changing Indian scenario. J Indian Med Assoc. 2001;99:634-7.

5. Revicky V, Muralidhar A, Mukhopadhyay S, Mahmood T. A case series of uterine rupture: Lessons to be learned for future clinical practice. J Obstet Gynaecol Ind. 2012;62:665-73.

Cite this article as: Bandyopadhyay S, Singh S. Rupture uterus: a clinical analysis. Int J Reprod Contracept Obstet Gynecol 2016;5:2183-6. 